\title{
Effect of Moisture Content and Heat Treatment on Peroxide Value and Oxidative Stability of Crude Palm Kernel Oil
}

\author{
Akinoso Rahman*, Aremu Ademola Kabir ${ }^{\mathrm{b}}$ and Raji Abdulganiy Olayinkab

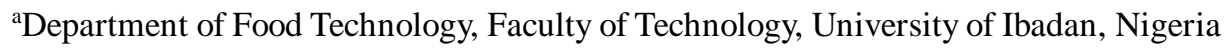 \\ ${ }^{b}$ Department of Agricultural and Environmental Engineering, Faculty of Technology, \\ University of Ibadan, Nigeria
}

(received March 27, 2010; revised October 21, 2010; accepted November 1, 2010)

\begin{abstract}
Effect of moisture content, roasting time and temperature on peroxide value (PV) and oxidative stability (OS) of unrefined palm kernel oil was studied using response surface methodology at five levels of moisture content $(4,7,10,13$ and $16 \%$ wet basis), roasting time $(5,10,15,20$ and 25 min) and roasting temperature (50, 70, 90, 110 and $\left.130{ }^{\circ} \mathrm{C}\right)$. Within the studied range, mean PV of palm kernel oil was recorded to be $13.06 \pm 5.13 \mathrm{meq} / \mathrm{kg}$. Least PV of $7.3 \mathrm{meq} / \mathrm{kg}$ was obtained at $10 \%$ moisture content, $15 \mathrm{~min}$ roasting time and $130{ }^{\circ} \mathrm{C}$ temperature. Maximum stability time of $27.0 \mathrm{~h}$ was achieved at $10 \%$ moisture content, 15 min roasting at $130{ }^{\circ} \mathrm{C}$. This treatment produced unrefined palm kernel oil stable for 388 days. All the studied parameters significantly influenced flavour rating and shelf life of unrefined palm kernel oil at $\mathrm{P} \leq 0.05$.
\end{abstract}

Keywords: palm kernel oil, oxidative stability, peroxide value, moisture, heat treatment

\section{Introduction}

Vegetable oil, as a valuable part of a well-balanced diet, contains a range of fat soluble vitamins (A, D, E and K) and essential fatty acids, both necessary for the healthy functioning of the body (Fellows and Hampton, 2003). Good quality palm kernel oil serves the aforementioned nutritional significance. Industrial application of palm kernel oil is also fast increasing. Among the 17 commodity covered in the data provided by Oil World (2009), palm kernel oil occupied eleventh production level, after four major vegetable oils (soy, palm, rape, and sunflower), three animal fats (tallow, lard and butter) and three minor oils (groundnut, cotton seed and coconut).

Palm kernel oil is a yellowish white fat containing $82 \%$ proportional weight of saturated fatty acid and 18\% unsaturated fatty acid (O’Brien, 2008). It is classified by the nutritional experts as saturated oil and has the advantage of having solid texture at room temperature (Rossell et al., 1985). Chemicals and physical properties of palm kernel oil resemble those of the coconut oil. It belongs to members of a group called lauric oils due to high level of lauric acid (46-52\%) present in proportional weight (Tat and Eng, 1985).

Preferences for fat and oil products with fresh bland flavours and odours require keeping quality and rancidity evaluations both during development and

*Author for correspondence; E-mail: akinoso2002 @ yahoo.com processing. Peroxide value (PV) is one of the most widely used chemical tests for the determination of fats and oils quality. Peroxide value is a measure of rancidity in its early stage, this test showed good corelation with organoleptic flavour scores (O'Brien, 2008). Although a linear relationship has been observed between peroxide values and flavour scores during the initial stages of lipid oxidation, this method alone is not a very good flavour quality indicator because the peroxide value increases to maximum and then decreases as storage time increases (Hill, 1994). Hence, oils and fats are subjected to oxidative stability test which is a good quality parameter assessment that complements PV analysis (Shahidi and Naczk, 2004; Holser and Isbell, 2000). Most fat and oil products are tested for flavour stability as part of quality control programmes to assure that customer specifications are satisfied. The purpose of this evaluation is to satisfactorily determine the product shelf life. Studies have been carried out on oxidative stability of edible fats and oils such as sesame oil (Lee et al., 2010), safflower oil (Lee et al., 2004), olive husk oil (Lucas et al., 2002), meadow foam oil (Holser and Isbell, 2000), cotton seed (Hill, 1994) and lard (Kikugawa et al., 1983). In summary, these reports showed oxidative stability of fats and oils dependent on the method used for determination of chemical composition and processing parameters. 
For oil expression, raw material preparation involves operations such as decortication, winnowing, cracking, pulping, and conditioning. Conditioning of oil seeds is an important operation in the production line of palm kernel oil. These activities include roasting, flaking and size reduction, cooking, pre-pressing and drying. Dehydrating and roasting of palm kernel before oil expression improves palm kernel oil yield (Akinoso et al., 2006; Ajibola, 1989). There is a need to establish the degree of influence of these parameters on storage life of the expressed crude palm kernel oil. This work investigated effects of moisture content, roasting time and temperature on the initial quality and the oxidative stability of unrefined palm kernel oil using response surface methodology. Calabar variety of palm kernel was used for the research work. The choice of the species was influenced by NIFOR (2008) report which stated that tenera variety of oil palm of calabar will soon be the major oil palm available for kernel crushing in Nigerian market due to its acceptability by organised palm oil industries in the country.

\section{Materials and Methods}

Experimental design. The experiment was conducted using central composite rotatable design as described by Montgomery (2005). Moisture content, roasting time and temperature were independent variables, while peroxide value and oxidative stability of the oil were the dependent variables. Fixing of independent parameter levels were based on preliminary work (Akinoso et al., 2006). Fifteen level combinations were used; the last level was repeated 6 times (Table 1) thus a total of 20 runs were conducted.

Material preparation. Palm kernel was obtained from Ogun State Ministry of Agriculture and Cooperative (Apoje oil mill), Nigeria. It was cleaned manually to remove foreign materials such as shell, broken kernels and stone.

Determination of moisture content. Initial moisture content of the seed was determined using ASABE (2008) method. Three samples each weighing $15 \mathrm{~g}$, were placed in an oven set at $130^{\circ} \mathrm{C}$ for $6 \mathrm{~h}$. The samples were then cooled in a glass jar containing silica gel as desiccant. The dried samples were weighed and the difference in weight before and after drying was taken as the moisture loss. Ratio of moisture loss to weight of wet material (percentage) was recorded as moisture content on wet basis. The desired moisture content levels were achieved by adding distilled water as calculated from below mentioned equation 1 (Akinoso et al., 2006). Samples were individually sealed in separate polyethylene bags and kept at $5{ }^{\circ} \mathrm{C}$ in a refrigerator for $12 \mathrm{~h}$ for distribution of moisture uniformly throughout the samples. Five moisture content levels viz. 4, 7, 10, 13 and $16 \%$ (wet basis) were prepared for each set:

$$
\mathrm{Q}=\mathrm{A}(\mathrm{b}-\mathrm{a}) /(100-\mathrm{b}) \text {. }
$$

where:

$$
\begin{aligned}
& \mathrm{A}=\text { Initial mass of the sample } \\
& \mathrm{a}=\text { Initial moisture content of the sample (\% wet } \\
& \quad \text { basis) } \\
& \mathrm{b}=\text { Final (desired) moisture content of sample } \\
& \quad(\% \mathrm{wb}) \\
& \mathrm{Q}=\text { Mass of water to be added }(\mathrm{kg})
\end{aligned}
$$

Pre-heating time and roasting temperature. Roasting temperature stability was achieved by Akinoso and Igbeka (2007) method. The product's initial temperature was raised to equilibrium with roasting temperature. This was achieved by wrapping them in polythene bags and placed in convection oven (Model LDO25OF, Win Science, Seoul, Korea) at the desired roasting temperature level. These samples were later heated by spreading thinly on a heat conductor tray in the oven at the preset temperature. The samples were heated at specified temperature and time. Stopwatch was used to monitor the time. Roasting time was 5 , 10, 15, 20 and $25 \mathrm{~min}$, while roasting temperature was 50, 70, 90, 110 and $130{ }^{\circ} \mathrm{C}$.

Oil expression. The expeller used was Tite 002 manufactured by Tiny Tech Plant, India, of a rated capacity of $180 \mathrm{~kg} / \mathrm{h}$, powered by a $30 \mathrm{~kW}$ electric motor with interchangeable speed. It consisted of a helical thread that revolved within a stationary perforated cylinder. The experiment was conducted through running the screw press for about $3 \mathrm{~min}$ before loading the pretreated samples of palm kernel. The oil seed was forced through the barrel by the action of the revolving worms. The volume was axially displaced by the worm, from the feeding end to the discharge end, thus compressing the meal as it passes through the barrel. The expelled oil drained through the perforation of the lining bars of the barrel, while the deoiled cake was discharged through the annular orifice. The expressed oil was collected and clarified by allowing it to stand for $96 \mathrm{~h}$. The clarified oil was then bottled and labelled.

Peroxide value. The peroxide value (PV) of unrefined palm kernel oil was determined by modified American 
Oil Chemists' Society standard method Cd 8-53 (AOCS, 1997). About $5 \mathrm{~mL}$ of oil was placed on a test paper (Matsushita, 1978). About $10 \mathrm{~mL}$ of water was added to the paper on which the oil has been placed. The intensity of the blue colour, developing on the test paper, was proportional to the peroxide value of the oil. Colour of the paper was compared to a predetermined standard as reported by Matsushita (1978).

Oxidative stability. Oxidative stability (OS) was evaluated by AOCS method Cd 12b-92 (AOCS, 1997) using Rancimat 679 apparatus (Metrohm AG, Herison, Switzerland). The evaluation procedure was performed by placing $2 \mathrm{~g}$ of the oil in the sample tube, which was preheated to $120^{\circ} \mathrm{C}$, connected on one side to the air source and on the other side to $50 \mathrm{~mL}$ cell of deionized water. Conductance of the water over time was measured automatically with data logger. Stability was expressed as the oxidation induction period in hours.

Data analysis. The experimental procedures were repeated thrice for each treatment and mean values of the data were recorded. Interaction between the inde- pendent and dependent variables was analysed by response surface methodology (RSM) using DesignExpert ${ }^{\circledR} 8$ software. Analysis of variance (ANOVA) and regression analysis were carried out and model equations were also developed. Level of significance was preset at 0.05 (95\% confidence level) for the entire analytical values.

\section{Results and Discussion}

Peroxide value. Within the studied range, recorded mean PV of palm kernel oil was $13.06 \pm 5.13 \mathrm{meq} / \mathrm{kg}$ (Table 1). Least PV of $7.3 \mathrm{meq} / \mathrm{kg}$ was obtained at $10 \%$ wb moisture content, 15 min roasting time and $130{ }^{\circ} \mathrm{C}$ roasting temperature while $16 \%$ wb moisture content, 15 min roasting time and $90^{\circ} \mathrm{C}$ roasting temperature gave the highest PV of $21.9 \mathrm{meq} / \mathrm{kg}$. Difference in the $\mathrm{PV}$ may be associated with variation in the roasting temperature and the moisture content of the samples. It is known that factors such as temperature, light, moisture, metals and oxygen affect the rate of oxidation (Salunkhe et al., 1992). Peroxide value of $7.3 \mathrm{meq} / \mathrm{kg}$ is within recommended/permissible PV of edible oil by $\mathrm{FAO} /$

Table 1. Central composite rotable design of the experiment showing variables and response

\begin{tabular}{|c|c|c|c|c|c|c|c|}
\hline $\begin{array}{l}\text { MC } \\
\text { (\%wb) } \\
\text { Coded }\end{array}$ & $\begin{array}{l}\text { RD } \\
\text { (min.) } \\
\text { Coded }\end{array}$ & $\begin{array}{l}\mathrm{RT} \\
\left({ }^{\circ} \mathrm{C}\right) \\
\text { Coded }\end{array}$ & $\begin{array}{l}\text { MC } \\
\text { (\%wb) } \\
\text { Real }\end{array}$ & $\begin{array}{l}\text { RD } \\
\text { (min.) } \\
\text { Real }\end{array}$ & $\begin{array}{l}\text { RT } \\
\left({ }^{\circ} \mathrm{C}\right) \\
\text { Real }\end{array}$ & $\begin{array}{l}\text { PV } \\
\text { (meg/kg) }\end{array}$ & $\begin{array}{l}\text { OS } \\
\text { (h) }\end{array}$ \\
\hline-1 & -1 & -1 & 7 & 10 & 70 & $10.6 \pm 1.2$ & $19.4 \pm 5.7$ \\
\hline-1 & -1 & 1 & 7 & 10 & 110 & $9.0 \pm 1.1$ & $23.1 \pm 3.6$ \\
\hline-1 & 1 & -1 & 7 & 20 & 70 & $8.6 \pm 0.9$ & $22.0 \pm 5.8$ \\
\hline-1 & 1 & 1 & 7 & 20 & 110 & $8.8 \pm 2.1$ & $25.9 \pm 3.9$ \\
\hline 1 & -1 & -1 & 13 & 10 & 70 & $16.2 \pm 3.3$ & $15.0 \pm 3.7$ \\
\hline 1 & -1 & 1 & 13 & 10 & 110 & $19.1 \pm 1.7$ & $14.7 \pm 2.1$ \\
\hline 1 & 1 & -1 & 13 & 20 & 70 & $18.3 \pm 2.9$ & $16.3 \pm 3.2$ \\
\hline 1 & 1 & 1 & 13 & 20 & 110 & $14.8 \pm 3.7$ & $17.6 \pm 4.5$ \\
\hline 1.682 & 0 & 0 & 16 & 15 & 90 & $21.9 \pm 4.1$ & $2.3 \pm 1.1$ \\
\hline-1.682 & 0 & 0 & 4 & 15 & 90 & $7.5 \pm 1.5$ & $24.6 \pm 2.6$ \\
\hline 0 & 1.682 & 0 & 10 & 25 & 90 & $17.2 \pm 2.9$ & $21.1 \pm 4.2$ \\
\hline 0 & -1.682 & 0 & 10 & 5 & 90 & $19.9 \pm 3.8$ & $16.3 \pm 3.8$ \\
\hline 0 & 0 & 1.682 & 10 & 15 & 130 & $7.3 \pm 1.9$ & $27.0 \pm 5.1$ \\
\hline 0 & 0 & -1.682 & 10 & 15 & 50 & $14.2 \pm 1.1$ & $18.3 \pm 3.8$ \\
\hline 0 & 0 & 0 & 10 & 15 & 90 & $11.2 \pm 1.2$ & $21.3 \pm 3.2$ \\
\hline 0 & 0 & 0 & 10 & 15 & 90 & $11.8 \pm 2.1$ & $21.9 \pm 3.8$ \\
\hline 0 & 0 & 0 & 10 & 15 & 90 & $10.9 \pm 1.3$ & $20.9 \pm 4.1$ \\
\hline 0 & 0 & 0 & 10 & 15 & 90 & $11.7 \pm 1.9$ & $21.6 \pm 3.2$ \\
\hline 0 & 0 & 0 & 10 & 15 & 90 & $11.3 \pm 1.8$ & $20.6 \pm 3.0$ \\
\hline 0 & 0 & 0 & 10 & 15 & 90 & $11.4 \pm 1.9$ & $21.5 \pm 3.6$ \\
\hline
\end{tabular}

MC = moisture content; $\mathrm{RD}$ = roasting time; $\mathrm{RT}$, roasting temperature; $\mathrm{PV}=$ peroxide value; $\mathrm{OS}$ = oxidative stability. 
WHO codex alimentarious standard. The maximum permissible level is $10 \mathrm{meq} / \mathrm{kg}$ (CAC, 2001).

Statistical analysis of the collected data showed the model to be significantly fit for the response surface quadratic model. Mathematical expression of relationship between the actual values of the variables and the response is shown as below given equation 2. Coefficient of determination $\mathrm{R}^{2}$ of the model was 0.8 . High coefficient of determination implies that, as a result of application of this mathematical equation errors will be minimal. Significant model terms of the equation at $\mathrm{P}=$ 0.05 were moisture content and the $2^{\text {nd }}$ order of roasting time. This agreed with the findings of Gunstone (2002) that isolated moisture content is the major stimulant of rancidity in some edible oils.

$P V=+35.14-1.64 m-2.25 r-0.08 t-2.15 \times 10^{-16} \mathrm{mr}$ $+1.67 \times 10^{-3} \mathrm{mt}-5.75 \times 10^{-3} \mathrm{rt}+0.14 \mathrm{~m}^{2}+0.09 \mathrm{r}^{2}+$ $5.65 \times 10^{-4} t^{2}$

Three dimensional view of the response to the variables are shown in Fig. 1 to 3. These plots help to visualize the shape of the response surface and give useful information about the fit model. The outlook of the response surface plots (Fig. 1-3) indicated that the centre was saddle and was neither maximum nor minimum. This explained why response surface quadratic model was fit to predict the PV of expressed palm kernel oil as affected by treatments.

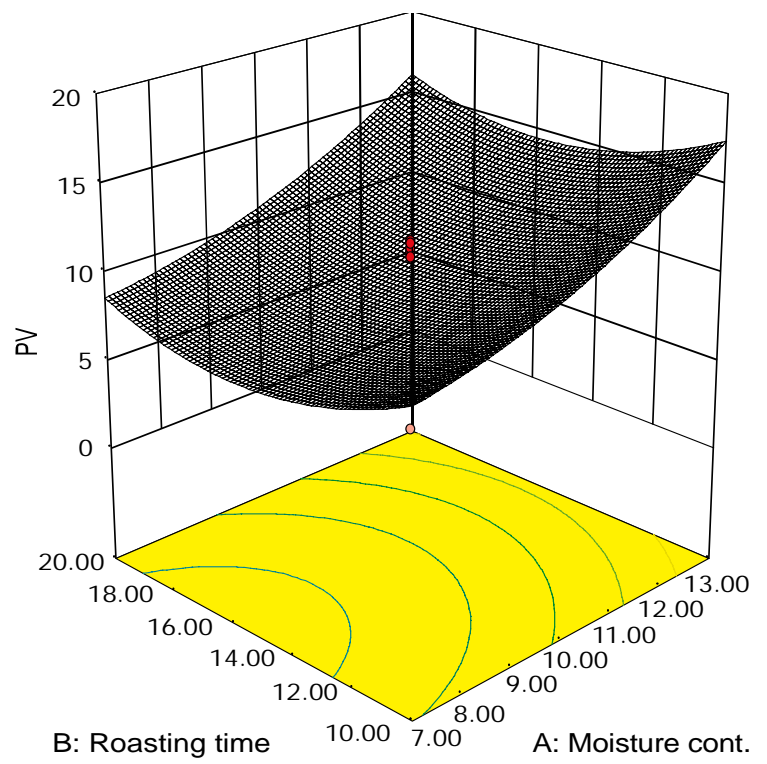

Fig. 1. Peroxide value of crude palm kernel oil as influenced by moisture content and roasting time.
It could be seen in Fig. 1 and 2 that the PV of oil increased with the moisture content. According to Goh (2002), disadvantage of using palm kernel oil in the presence of moisture and lipase enzyme is the hydrolytic reaction that liberates short-chain fatty acids

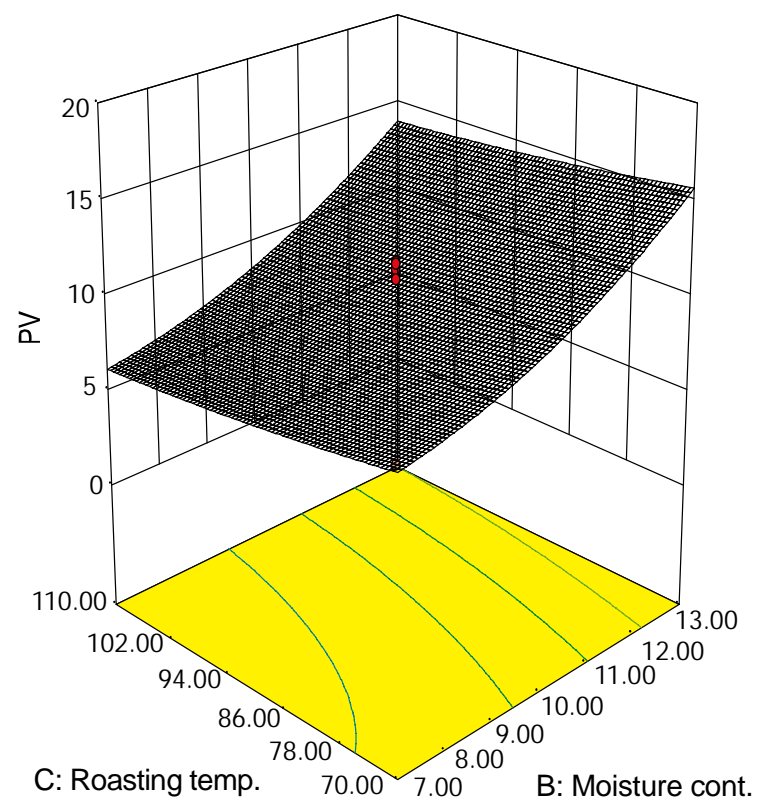

Fig. 2. Peroxide value of crude palm kernel oil as influenced by moisture content and roasting temperature.

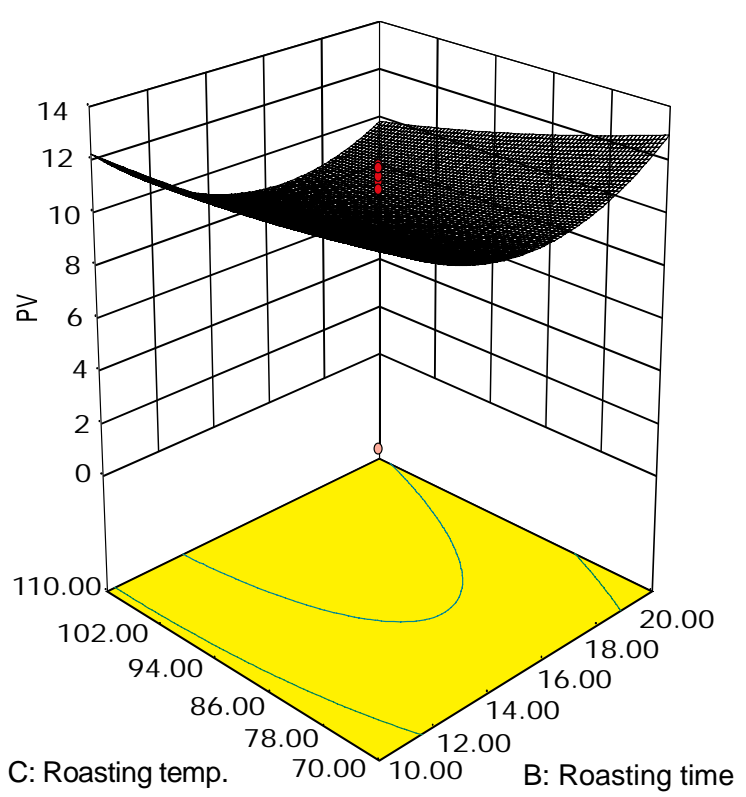

Fig. 3. Peroxide value of crude palm kernel oil as influenced by roasting time and temperature. 
(C 6:0 to C 12:0) and gives rise to unpleasant soapy off-flavour. This phenomenon explained the observed trend of the plots (Fig. 1 and 2).

Response to the heat treatment as shown in Fig. 3 was non-proportional variation. That is, neither continuous increase nor decrease in PV of the oil samples was experienced with the increase in roasting time and temperature. This suggested unsteady thermal influence on the reaction. As expected, a biological material like palm kernel displayed non homogeneous behaviour; as behaviour similar to the one shown in Fig. 3 was reported by Guillen and Cabo (2002) on PV of safflower, sunflower, rape seed and olive oils. Formation of PV is a chemical reaction, and like most reactions, it is influenced by heat, light and impurities.

Oxidative stability. With treatment at $16 \%$ moisture content for $15 \mathrm{~min}$ roasting time at $90{ }^{\circ} \mathrm{C}$ roasting temperature, minimum oxidative time of $2.3 \mathrm{~h}$ was recorded while maximum oxidative time of $27.0 \mathrm{~h}$ was achieved at $10 \%$ moisture content, 15 min roasting time and 130 ${ }^{\circ} \mathrm{C}$ roasting temperature. One hour of active oxygen is equivalent to 15 days (O'Brien, 2008); using this conversion factor, the oil in its form can retain its flavour for 388 days. This quality may be traced to the presence of tocopherol in palm kernel oil and also to its saturation. The degree of saturation is known to significantly influence lipid oxidation. Tocopherol is a natural antioxidant and has impact on oxidative stabi-lity of oils (Otal, 2001; Kamal-Eldin and Appelqvist, 1996).

A response surface quadratic model was used to illustrate the relationship between the oxidative stability (response), moisture content, roasting time and temperature (variables) (equation 3). Lack of fit and F-value of the model are significant. Also the coefficient of determination $\mathrm{R}^{2}(0.99)$ of the model was high.

$\mathrm{OS}=-4.69+4.17 \mathrm{~m}+0.87 r+0.1 t-1.0 \times 10^{-2} \mathrm{mr}-$

$1.37 \times 10^{-2} m t+2.25 \times 10^{-3} r t-0.21 m^{2}-0.02 r^{2}+$ $9.5 \times 10^{-4} t^{2}$

The coefficient of determination $R^{2}(0.99)$ of the model indicated suitability of the application of the model in predicting effect of moisture content, roasting time and temperature on OS of palm kernel oil. ANOVA of the data revealed that the three independent variables and the $2^{\text {nd }}$ order of moisture content were significant model terms at $\mathrm{P}=0.05$. This implies that variation in any of the variables, will bring noticeable difference in oxidative stability of palm kernel oil.
Visual outputs of the interaction are shown in Figs. 4-6. Reduction in OS time was observed with the increase in moisture content of palm kernel oil (Fig. 4 and 5). Moisture naturally accelerates hydrolysis reaction (Hui, 1996). This accounts for the reduced oxidative stability time with the increase in moisture content.

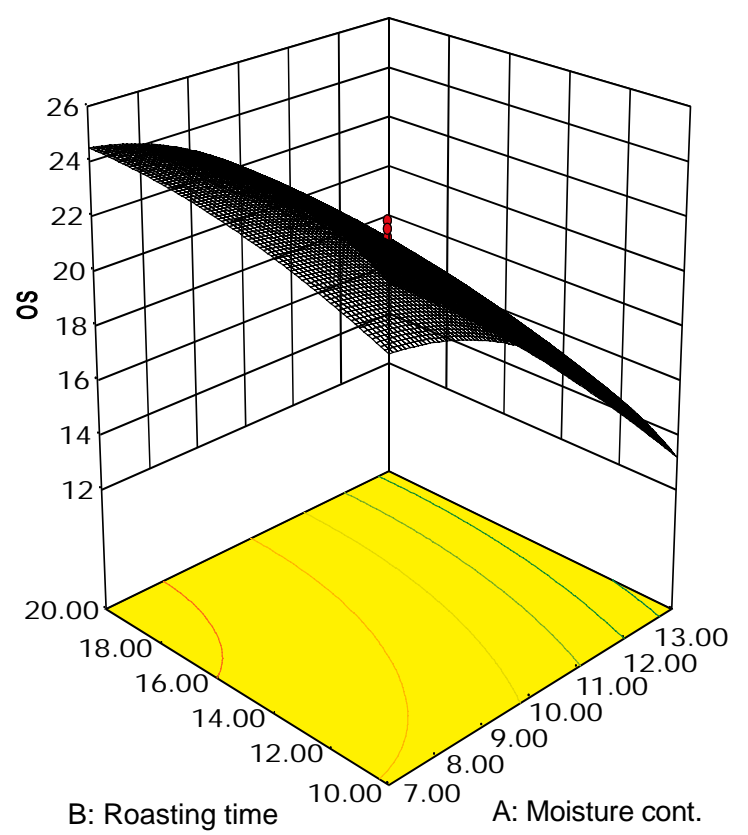

Fig. 4. Oxidative stability (OS)of crude palm kernel oil as influenced by moisture content and roasting time.

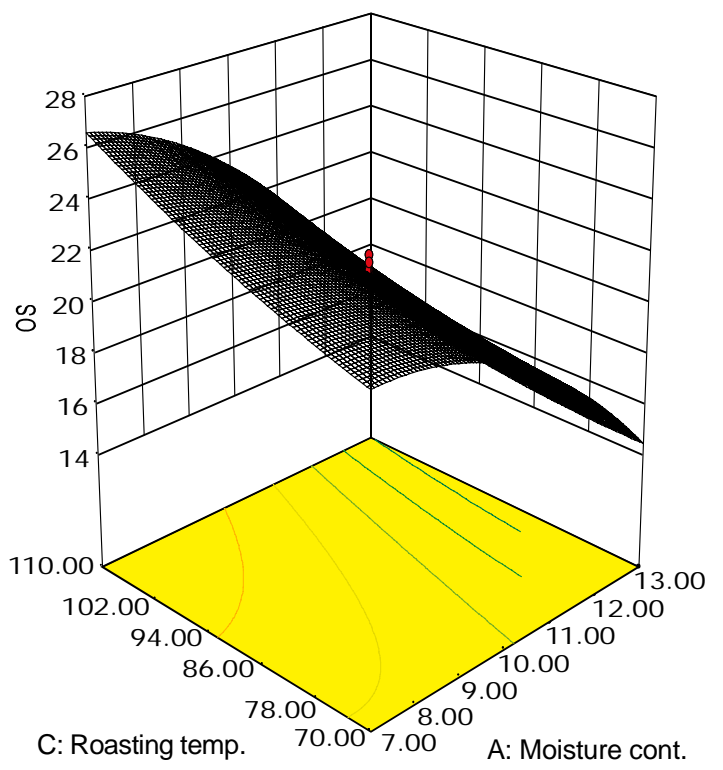

Fig. 5. Oxidative stability (OS) of crude palm kernel oil as influenced by moisture content and roasting temperature. 
Heat treatment (Fig. 6) showed a trend converse to as shown in Fig. 4 and 5. Potencies of tocopherol, a natural antioxidant in palm kernel, are temperature dependent (Hove and Hove, 1944). This may account for the observed behaviour.

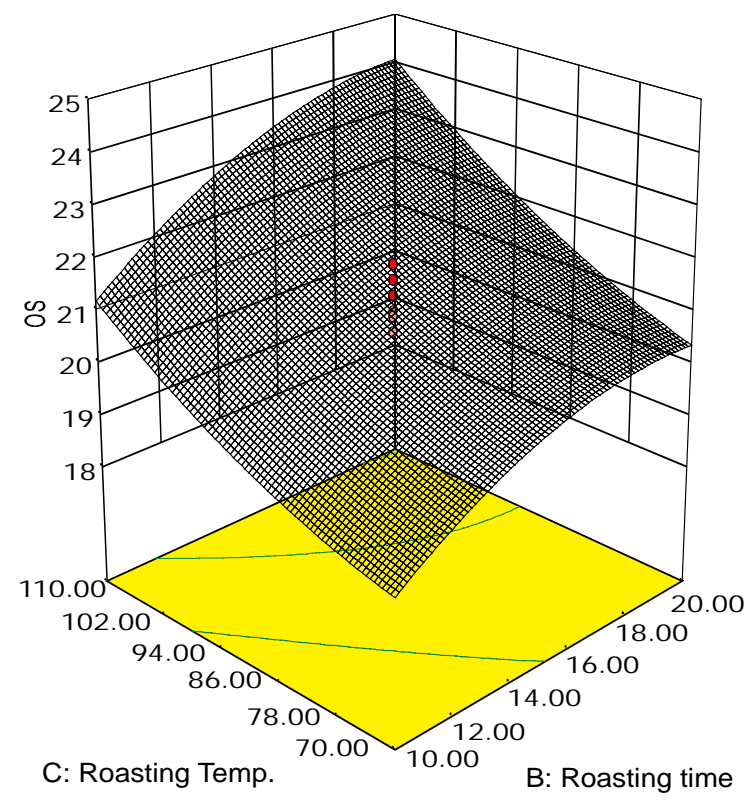

Fig. 6. Oxidative stability (OS) of crude palm kernel oil as influenced by roasting time and temperature.

\section{Conclusion}

Initial moisture content of palm kernel and conditioning of palm kernel by heating significantly affected the flavour rating viz peroxide value and stability of unrefined palm kernel oil at $\mathrm{P} \leq 0.05$. The degree of influence of these treatments on peroxide value and oxidative stability of palm kernel oil can be predicted using response surface quadratic model. Maximum oxidative time of $27.0 \mathrm{~h}$ was achieved at $10 \%$ moisture content, 15 min roasting time and $130{ }^{\circ} \mathrm{C}$ roasting temperature. This treatment produced unrefined palm kernel oil that will be stable for 388 days before usage.

\section{References}

Ajibola, O.O. 1989. A study of some factors affecting the hydraulic pressing of palm kernel. Journal of Food Science Technology (India), 26: 213-217.

Akinoso, R., Igbeka, J.C., Olayanju, T.M.A., Bankole, L.K. 2006. Modeling of oil expression from palm kernel (Elaeis guneensis Jacq.). Agricultural Engineering International - The CIGR Ejournal,
Manuscript FP 05 016, vol. VIII.

Akinoso, R., Igbeka, J.C. 2007. Optimisation of oil expression from palm kernel. Journal of Food Science and Technology, 44: 360-362.

AOCS 1997. The Official Methods and Recommended Practices of the American Oil Chemists Society, $4^{\text {th }}$ edition, American Oil Chemists Society. Champaign, IL, USA.

ASABE 2008. Moisture Measurement, Peanut American Society of Agricultural and Biological Engineers, ASAE S410.1 DEC 1982 (R2008), 679-680.

CAC 2001. Fats, Oils and Related Products, vol. 8, $2^{\text {nd }}$ edition, (revised 2001), Codex Alimentarius Commission, Joint FAO/WHO Food Standard Programme, ALINORM.

Fellows, P., Hampton, A. 2003. Small Scale Food Processing: A Guide to Appropriate Equipment, pp. 40-45, $2^{\text {nd }}$ edition, Intermediate Technology Publication, London, UK.

Gunstone, F.D. 2002. Vegetable Oils. In: Food Technology: Composition, Properties and Uses, 337 pp., $1^{\text {st }}$ edition, Blackwell Publishing, Oxford, UK.

Goh, E.M. 2002. Applications and uses of palm and palm kernel oils in specialty products. Malaysian Oil Science Technology, 11: 46-50

Guillen, M.D., Cabo, N. 2002. Fourier transforms infrared spectra data versus peroxide and anisidine values to determine oxidative stability of edible oils. Food Chemistry, 77: 503-510.

Hill, S.E. 1994. Comparisons: measuring oxidative stability. Inform, 5: 104-109.

Holser, R.A., Isbell, T.A. 2000. Effect of processing condition on the oxidative stability of meadow foam press oil. Journal of the American Oil Chemists Society, 79: 1051-1052.

Hove, E.L., Hove, Z. 1944. The effect of temperature on the relative antioxidant activity of $\alpha$-, $\beta$-, and $\gamma$ - tocopherols and gossypol. The Journal of Biological Chemistry, 156: 623-632.

Hui, Y.H. 1996. Edible oil and fat products processing technology. In: Bailey's Industrial Oil and Fat Products, Y.H. Hui (ed.), vol. 4, $5^{\text {th }}$ edition, John Wiley and Sons Inc., New York, USA.

Kamal-Eldin, A., Appelquist, LA. 1996. The chemistry and antioxidant properties of tocopherol and tocotrienols. Lipids, 31: 671-701.

Kikugawa, K., Arai, M., Kurechi, T. 1983. Participation of sasamol in stability of sesame oil. Journal of the American Oil Chemists Society, 60: 1528-1533. 
Lee, S.W., Jeung, M.K., Park, M.H., Lee, S.Y., Lee, J. 2010. Effect of roasting conditions of sesame seeds on the oxidative stability of pressed oil during thermal oxidation. Food Chemistry, 118: 681-685.

Lee, Y., Oh, S., Chang, J., Kim, I. 2004. Chemical composition and oxidative stability of safflower oil prepared from safflower seed roasted with different temperatures. Food Chemistry, 84: 1-6

Lucas A. de, Rincon J., Gracia, I. 2002. Influenced of operating variables on yield and quality parameters of olive husk oil extracted with supercritical carbon dioxide. Journal of the American Oil Chemist Society, 79: 237-243.

Matsushita, S. 1978. Peroxide Value Determining Test for Oils and Fats, US Patent No. 4, 098, 575, $4^{\text {th }}$ July, 1978.

Montgomery, D.C. 2005. Design and Analysis of Experiments: Response Surface Method and Designs, John Wiley and Sons Inc., New Jersey, USA.
NIFOR, 2008. Annual Report of Nigerian Institute of Oil Palm Research, Benin City, Nigeria.

O'Brien, R.D. 2008. Fats and Oils, Formulating and Processing for Application, Technical Publishing, Company Inc. Lancaster, USA.

Otal, 2001. Commodity News-Palm/Domestic Oil http:/ /www. Otal. Com/coil palm.htm.

Rossel, J.B., King, B., Downes, M.J. 1985. Composition of oil. Journal of the American Oil Chemist Society, 62: 221-229.

Salunkhe, D.K., Chavan, J.K., Adsule, R.N., Kadam, S.S. 1992. World Oilseeds: Chemistry, Technology and Utilization, Van Nostrand Reinhold, New York, USA.

Shahidi, F., Naczk, M. 2004. Phenolics in Food and Nutraceuticals, pp. 108-109, CRC Press, Boca Raton, Florida, USA.

Tat, M.M., Eng, T.G. 1985. Quality control in oil palm fruits processing. Journal of the American Oil Chemist Society, 62: 274-282. 